FREIRIA, L.B. et al. Exigências nutricionais e eficiência energética para vacas de corte.

PUBVET, Londrina, V. 8, N. 9, Ed. 258, Art. 1714, Maio, 2014.

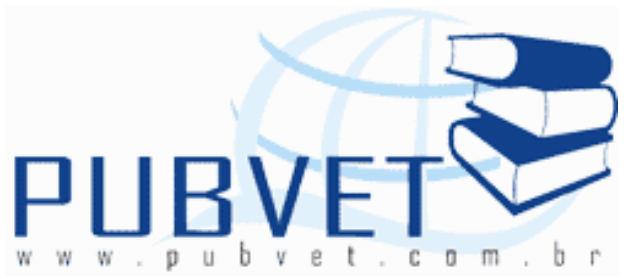

PUBVET, Publicações em Medicina Veterinária e Zootecnia.

\title{
Exigências nutricionais e eficiência energética para vacas de corte
}

Lucien Bissi da Freiria ${ }^{1}$, Adriano Jorge Possamai ${ }^{1}$, Pedro Ivo Jose Lopes da Rosa e Silva ${ }^{2}$, Joanis Tilemahos Zervoudakis ${ }^{3}$

1 Discentes mestrado no programa de Pós-graduação em Ciência Animal (PPGCA -UFMT).

${ }^{2}$ Discente Graduação em Medicina Veterinária pela Universidade Federal de Mato Grosso

3 Professor do Departamento de Ciências Básicas e Produção Animal da Universidade Federal de Mato Grosso (DCBPA -UFMT).

Autor para correspondência: Lucienbissi@hotmail.com

\section{Resumo}

Objetivou-se avaliar os estudos referentes às exigências nutricionais e eficiência energética de vacas Nelore, relatando dados dos requerimentos das frações de energia e proteína para estes animais na fase da gestação e lactação. Pouco se sabe sobre as exigências nutricionais de vacas de corte criadas em condições tropicais, muitos dados ainda são fundamentados de pesquisas com animais europeus em condições temperadas, sub ou super estimando os valores que possivelmente poderão ser encontrados em condições brasileiras. Com isso, se utilizou das equações obtidas por estudos realizados no Brasil para produção de tabelas com as exigências de energia líquida, energia metabolizável, nutrientes digestíveis totais para mantença e 
FREIRIA, L.B. et al. Exigências nutricionais e eficiência energética para vacas de corte. PUBVET, Londrina, V. 8, N. 9, Ed. 258, Art. 1714, Maio, 2014.

ganho de peso, com base em vacas em diferentes estágios de gestação, lactação e tamanho corporal. Assim como para as frações de proteína. Com base nos dados encontrados conclui-se que no terço final da gestação ocorre o aumento expressivo na exigência de energia e proteína, e vacas lactantes tem uma demanda que supera sua capacidade ingestiva, para um ganho de 1 $\mathrm{kg} /$ dia com CMS em torno de $2 \%$ do peso corporal.

Palavras-chave: consumo, gestação, lactação, tamanho corporal

\title{
Nutritional requirements and energy efficiency of beef cows
}

\begin{abstract}
Review studies related to nutritional and energy efficiency of cow Nellore, data reporting requirements of the fractions of energy and protein for these animals during gestation and lactation. Little is known about the nutritional requirements of beef cows raised in tropical conditions, many data are still based animal research in European temperate conditions, under or over estimating the values that could possibly be found in Brazilian conditions. With this, we used the equations obtained by studies conducted in Brazil to produce tables with the net energy requirements, energy metabolizable, total digestible nutrients for maintenance and gain weight, based on cows in different stages of pregnancy, lactation and size body. As for the protein fractions. Based on the data obtained it is concluded that in the last third of gestation is the significant increase in demand for energy and protein, and lactating cows have a demand that exceeds their ingestive capacity, for a gain of $1 \mathrm{~kg} /$ day with CMS around $2 \%$ of body weight.
\end{abstract}

Keywords: intake, pregnancy, lactation, size body

\section{INTRODUÇÃO}

A pecuária brasileira tem grande expressividade, o país é detentor de um rebanho de aproximadamente 209 milhões de cabeça, ocupando 20\% do 
FREIRIA, L.B. et al. Exigências nutricionais e eficiência energética para vacas de corte. PUBVET, Londrina, V. 8, N. 9, Ed. 258, Art. 1714, Maio, 2014.

território nacional, em sua maioria em regime à pasto, sendo estimado entorno $3 \%$ em sistema intensivo (ABIEC, 2011). E no ano de 2012, segundo dados do IBGE (2013), o país abateu 31,08 milhões de cabeças de bovinos, destinados para o mercado interno e para mais de 250 países.

Mas toda essa expressividade é corrompida quando se analise os índices zootécnicos, logo, a eficiência ainda não está em valores expressivos, pois dados os índices produtivos nacionais ainda são considerados baixos com elevada idade ao primeiro parto e ao abate. Para Oliveira (2006) as pressões impostas pela abertura de mercados, além da competição exercida por outros tipos de carnes e da concorrência por área pelas atividades agrícolas têm exigido maior eficiência do setor produtivo de carne bovina do Brasil.

Hoffmann (2007) define que alcançar maximização da eficiência de utilização de alimentos é fundamental para sucesso econômico do produtor, e a implantação de sistemas mais lucrativos e ecologicamente adequados, harmonicamente inseridos na cadeia produtiva e contexto social, dependem dos recursos e tecnologias disponíveis e também da gerencia desses meios. Alencar (2004) assume que para a sobrevivência ou permanência no negócio tem que produzir de forma eficiente e eficaz.

Neste intuito em alcançar maximização da eficiência se faz obrigatoriamente incrementar a produtividade e melhorar a rentabilidade dos sistemas de produção de carne bovina lançando a mão o conhecimento e aplicação de um manejo alimentar racional, e o que se torna necessário o conhecimento das exigências nutricionais (PAULINO, 2006).

NRC (2000), para exigências nutricionais bovinos de corte, determina que possam ser subdivididas em exigências para mantença, crescimento, gestação ou lactação.

A definição de exigência de energia para mantença é a quantidade energia ingerida que resultará em nenhuma perda ou ganho liquido de tecido corporal (HOFFMANN, 2007), e seu requerimento total de energia de mantença é função do consumo de energia metabolizável necessário para uma não alteração da energia corporal (PAULINO et al., 2010). 
FREIRIA, L.B. et al. Exigências nutricionais e eficiência energética para vacas de corte. PUBVET, Londrina, V. 8, N. 9, Ed. 258, Art. 1714, Maio, 2014.

A exigência de proteína metabolizável para mantença corresponde às perdas metabólicas fecais, urinárias, e por descamação do epitélio. É difícil quantificar essas perdas, principalmente, em relação às perdas metabólicas fecais, já que é necessário separá-las em fração microbiana e fração proveniente do alimento (HOFFMANN, 2007).

Bottje\&Carstens (2009), propõem que o "turnover" proteico, bomba de íons ( $\mathrm{Na}+, \mathrm{K}+$ por exemplo) e o desacoplamento da fosforilação oxidativa na mitocôndria (protonleakage) sejam responsáveis por aproximadamente 60$70 \%$ do total de energia requerida para mantença, que, em essência, simboliza a ineficiência energética dos animais.

Destacando a comparação entre raça, as exigências de energia de mantença de animais zebuínos em condições brasileiras são realmente inferiores dos animais taurinos. Os dados nacionais sugerem de forma bastante convincente que animais nelores demandam em torno de 10 a $22 \%$ menos energia para mantença do que animais taurinos (HOFFMANN, 2007). No tocante, animais Nelore, que tiveram uma maior evolução em número, pelo grande aporte de características de rusticidade, o que the conferem a capacidade de desenvolvimento corporal em consumo de alimento de baixa qualidade (ACNB, 2013).

De maneira geral, reportando dados de eficiência de produção de bovinos de corte, a fase de cria não pode ser subestimada, pode-se eventualizar que as exigências de mantença da vaca representam cerca de $70 \%$ da energia total gasta pela matriz durante o ano (Ferrel e Jenkins, 1985; Soliset al., 1988). Braga Neto (2013) propõe que a energia de mantença representou de 65 a $80 \%$, a lactação cerca de $15 \%$, e a gestação entre 5 e $10 \%$ das exigências anuais das vacas avaliadas. E essas exigências de mantença da mãe representam aproximadamente, $50 \%$ da energia necessária para a produção de um novilho no ponto de abate (Ferrell\& Jenkins, 1985).

O que tange como necessário conhecimento das exigências nutricionais das vacas. Conhecendo-as é possível aumentar a eficiência da produção em 
FREIRIA, L.B. et al. Exigências nutricionais e eficiência energética para vacas de corte. PUBVET, Londrina, V. 8, N. 9, Ed. 258, Art. 1714, Maio, 2014.

uma fase de criação que constitui base de todas as demais (FONSECA et al., 2012).

Reynolds (2000) orienta que a demanda dos diferentes órgãos e que define a partição de utilização dos nutrientes, seja para síntese ou para catabolismo. Assim, tecidos com alta taxa metabólica tem prioridade no direcionamento dos substratos. Para vacas lactantes, essa prioridade de direcionamento se dá as glândulas mamárias, que, por sua vez, é determinado pelo fluxo sanguíneo e pela concentração de nutrientes no sangue, e à capacidade de síntese de proteína no tecido mamário se relaciona com a utilização de aminoácidos (METCALF et al., 1996).

A produção de leite das vacas além de se torna prioridade na utilização de substratos, é uma característica importante na pecuária de corte, uma vez que grande parte dos nutrientes ingeridos pelos bezerros nos primeiros meses de vida provém do leite materno (BRAGA NETTO, 2013).

Com isso, conhecimento de necessidades energéticas e protéicas de vacas tanto no período gestacional como lactante, se faz necessário, para melhorar o desempenho de suas proles, como também promover uma maior eficiência do sistema de cria, melhorando a conversão de nutrientes ingeridos em peso de bezerro a desmame.

\section{EXIGÊNCIAS NUTRICIONAIS PARA VACAS DE CORTE GESTANTES}

No ambiente interno da fêmea, ligado aos aspectos fisiológicos, o desenvolvemento fetal ocorre de maneira exponencial e subsequente ao crescimento dos tecidos uterinos e placentários (NRC, 2000). E a influência danutrição maternalno desenvolvimentofetalé critriosa em algumas situações, ou seja,o fetopode sersubnutridoem mãesbem alimentadosquando 0 tamanhoou a funçãoda placentaé insuficientepara atender às demandasfetais.Por outro lado,mesmo que amãesofra de subnutrição, os sistemas maternaseplacentáriapodecompensartais,que a desnutriçãofetalé mínima (BASSETT, 1991). 
FREIRIA, L.B. et al. Exigências nutricionais e eficiência energética para vacas de corte. PUBVET, Londrina, V. 8, N. 9, Ed. 258, Art. 1714, Maio, 2014.

Assim, é importante cumprir as exigênciasnutricionais defêmeasgrávidasbovinas paraajustar uma ofertaadequadade nutrientespara o crescimento edesenvolvimento do fetoe à garantia deque a fêmeaestá em condiçãocorporal adequadapara parire amamentar sua prole,como também em dentro de 80 diasapósparto suscetível a reprodução, e em caso de fêmeas com doisou trêsanos de idade, deve se atentar a fornecer nutrientes adequadospara o crescimento continuado da progenitora (NRC, 2000).

\section{EXIGÊNCIA DE ENERGIA PARA VACAS DE CORTE GESTANTES}

Em definição segundo NRC (2000), as necessidades nutricionais para a gravidez são proporcionais ao peso de nascimento do bezerro, logo, fatores que afetam o peso do bezerro tem um efeito proporcional às exigências de nutrientes no período gestacional. Ferrell (1991) elenca esses fatores que afetam o peso do bezerro, incluindo raça do touro, raça da mãe,heterose, a paridade da progenitora,número de fetos, o sexo do feto, temperaturaambiental enutriçãoda progenitora. Dentre destes o que se posiciona com maior influência é a raça ou genótipo, ligado ao pai e a mãe, ou até mesmo do bezerro (ANDERSEN \& PLUM, 1965).

Nestes fatores de maior influência, dados reportados AFRC (1990), demostram a variação de pesos ano nascer de 31, 35, 38 e 43 kg, determinados pelas raças de corte, sendo elas Angus, Hereford, Limousin e Charolês, respectivamente, o que confirma a influência da raça. Para peso ao nascer de bezerros da raça Nelore, apresentam valor 28-30 kg (RIBEIRO et al. 1992; CUBAS et al., 2001; BOCCHI et al. 2004; SOUZA et al., 2010), o que demostram inferioridade de 10 á $12 \%$ em relação aos animais Bostaurustaurus.

Segundo Abrahão et al., (2000), ao fazerem 181 observações de pesos de bezerros ao nascer, pode notar que vacas mais pesadas produziram bezerros mais pesados. Alencar et al. (1999), ao registrarem 631 pesos ao desmame, observaram que vacas mais pesadas produzem mais leite, em consequência 
FREIRIA, L.B. et al. Exigências nutricionais e eficiência energética para vacas de corte. PUBVET, Londrina, V. 8, N. 9, Ed. 258, Art. 1714, Maio, 2014.

desmama bezerros mais pesados. Dentro deste fator progenitora, o condição corporal materna pode influenciar no peso ao nascer, NRC (2000) ao correlacionar o peso ao nascer comescore de condiçãovaca, assumiu que escores abaixo de 3,5 diminui e acima de 7 aumenta o peso ao nascer da prole, mas não se alteroudentro da faixade 3,5 a7 da condição corporal da vaca.

No sentido de importância de quantificar o peso ao nascer do bezerro, NRC (2000) na compilação de dados, orienta a calcular a exigência de energia líquida para mantença $\left(E L_{m}\right)$ para vacas no período gestacional em função dos dias de gestação e do peso do bezerro ao nascer (Tabela 1 ), com as equações: energia metabolizável, $E M=$ peso ao nascer $(0,4504-0,000766 \mathrm{t}) \mathrm{e}^{(0,03233-}$ $0,0000275 t) t, E L_{m}=0,576$ peso ao nascer $(0,4504-0,000766 t) e^{(0,03233-0,0000275 t) t}$, 0,576 valor deeficiênciadeutilização de energia metabolizávelpara manutenção $\left(K_{m}\right), K_{m}=N E_{m} / M E$ ou $K_{m}=\left(1,37 E M-0,138 \mathrm{EM}^{2}+0,0105 \mathrm{EM}^{3}-\right.$ $1,12) / E M$.

Tabela 1 - Estimativa de $\mathrm{EL}_{\mathrm{m}}$ (Mcal, dia) requerimento para a gravidez.

\begin{tabular}{ccc}
\hline Dias de gestação & NRC, $2000^{1}$ & NRC, $2000^{2}$ \\
\hline 130 & 0,327 & 0,255 \\
160 & 0,634 & 0,494 \\
190 & 1,166 & 0,908 \\
220 & 2,027 & 1,580 \\
250 & 3,3333 & 2,597 \\
280 & 5,174 & 4,031 \\
\hline 1Bezerros com peso ao nascer 38,5 kg; ${ }^{2}$ Bezerros com com peso ao nascer 28,5 kg (CUBAS et al.,
\end{tabular}

Para o NRC (1996) a energia líquida (EL) corresponde a 65\% da energia metabolizável $(E M)$, ou seja, $E L=E M \times 0,65$. Para Fonseca (2009) EM corresponde a $82 \%$ da energia digestível (ED), ou seja, EM = ED x 0,82, e ED 1 Mcal corresponde a 4,409 $\mathrm{kg}$ de NDT, com isso, reportando os dados da tabela 1 gera a Tabela (2) com dados de exigência de kg de NDT/dia. 
FREIRIA, L.B. et al. Exigências nutricionais e eficiência energética para vacas de corte.

PUBVET, Londrina, V. 8, N. 9, Ed. 258, Art. 1714, Maio, 2014.

Tabela 2 - estimativa de NDT ( $\mathrm{kg} / \mathrm{dia})$ requerimento para a gravidez.

\begin{tabular}{ccc}
\hline Dias de gestação & $\mathrm{NRC}, 2000^{1}$ & $\mathrm{NRC}, 2000^{2}$ \\
\hline 130 & 0,13 & 0,11 \\
160 & 0,26 & 0,21 \\
190 & 0,49 & 0,39 \\
220 & 0,86 & 0,67 \\
250 & 1,41 & 1,10 \\
280 & 2,20 & 1,72 \\
\hline
\end{tabular}

${ }^{1}$ Bezerros com peso ao nascer 38,5 kg; ${ }^{2}$ Bezerros com com peso ao nascer $30 \mathrm{~kg}$ (CUBAS et al., 2001).

\section{REQUERIMENTOS DE PROTEÍNA PARA VACAS DE CORTE GESTANTE}

A proteína é um dos nutrientes mais nobres para os seres vivos, estando envolvida em funções vitais diversas no organismo tais como: crescimento e reparo dos tecidos, catalise enzimática, transporte e armazenamento, movimento coordenado, sustentação mecânica, proteção imunitária, geração e transmissão de impulsos nervosos, controle do metabolismo, do crescimento e da diferenciação celular. Portanto, garantir adequado suprimento protéico aos animais significa provê-los de um nutriente essencial para manutenção de sua homeostase, propiciando a produção de carne de forma eficiente. (MARCONDES et al., 2010).

Necessidades de proteínas de vacas gestantes também são relatados pelo NRC (2000) numa compilação de resultados, definindo a participação do peso ao nascer do bezerro (PN), como também dias de gestação, sendo pela seguinte equação derivada de Ferrell et. al. (1976): $N=$ peso ao nascer $(0,001669-0,00000211 t) e^{(0,0278-0,0000176 t) t}$, essa determina a necidadede de nitrogênio e utilizando o fator de correção, $\mathrm{PB}=\mathrm{N} \mathrm{g/dia*6,25}$, para proteina metabolizável (Tabela 3). 
FREIRIA, L.B. et al. Exigências nutricionais e eficiência energética para vacas de corte. PUBVET, Londrina, V. 8, N. 9, Ed. 258, Art. 1714, Maio, 2014.

Tabela 3 - As estimativas deproteína metabolizável disponível necessáriapara a gravidezporvacas de corteem vários diasde gestação.

\begin{tabular}{ccc}
\hline Dias de gestação & $\begin{array}{c}\mathrm{PB}, \mathrm{g} / \mathrm{dia}(\mathrm{PN}, 38,5 \\
\mathrm{kg})\end{array}$ & $\mathrm{PB}, \mathrm{g} / \mathrm{dia}(\mathrm{PN}, 30 \mathrm{~kg})$ \\
\hline 130 & 14,1 & 11,1 \\
160 & 26,8 & 20,9 \\
190 & 48,9 & 38,1 \\
220 & 86,2 & 67,2 \\
250 & 146,7 & 114,3 \\
280 & 241,2 & 188,0 \\
\hline
\end{tabular}

\section{EXIGÊNCIAS NUTRICIONAIS PARA VACAS DE CORTE LACTANTES}

A produção de leiteem vacas de corte é difícil de avaliar. Em contraste comas vacas leiteira, que geralmente se faz ordenhada mecânica duas oumais vezes por dia, a vaca de corteé, em geral, criada em permanência no ambiente ápasto e o leiteproduzidoé consumido pelobezerro (NRC, 2000).

Inúmeros esforços são realizados para avaliara produção de leitede vacas de cortecombezerromamandocomo mínimo de perturbaçãoda rotinanormal davaca ebezerro, dentro dos métodos utilizados têm-se a ordenha manual, a ordenha mecânica ou manual após injeção de ocitocina, e por fim a pesagem do bezerro antes e após mamada (BEAL et al., 1990; MCCARTER et. al, 1991;JENKINS EFERRELL,1992; BAUMANN et al., 2004).Este métodos são realizados no intuito de predizer a produção de leite e composição do leite, o que favorece o ajuste de exigências nutricionais de vacas em lactação.

\section{EXIGÊNCIAS ENERGÉTICAS PARA VACAS DE CORTE LACTANTES}

A exigência de energia do animal inclui energia gasta para crescimento, terminação, prenhez e lactação, sendo fatores produtivos, mas também se tem aquela destinada para mantença (NRC, 2000). A definição de exigência de energia para mantença é a quantidade energia ingerida que resultará em nenhuma perda ou ganho liquido de tecido corporal (HOFFMANN, 2007). 
FREIRIA, L.B. et al. Exigências nutricionais e eficiência energética para vacas de corte. PUBVET, Londrina, V. 8, N. 9, Ed. 258, Art. 1714, Maio, 2014.

As variações das exigências de energia para mantença acompanham o comportamento das variações de peso (BRAGA NETTO, 2013). Isto se deve ao fato de que a principal variável envolvida no cálculo das exigências de energia para mantença é o peso corporal dos animais (NRC, 2000).

Em vacas em lactação, o requerimento de energia acompanha a produção e a composição do leite, principalmente no que se refere ao teor de gordura (BRAGA NETTO, 2013), logo, a predição de exigências energéticas para ganho de vacas de corte Lactantes, há necessidade do conhecimento da sua produção e composição do leite.

Pois, além de predizer sua exigência, com o conhecimento da produção de leite, estabelece-se a quantidade de energia secretada via leite que, por conseguinte, permite estimar quando seria o momento de suplementar os bezerros, ou seja, quando o suprimento de nutrientes via leite não estaria mais conseguindo suprir as necessidades dos bezerros para o ganho (PAULINO et al., 2006; FONSECA, 2009).

Nesta ótica o conhecimento do dispêndio energético para a produção de um quilo de bezerro a desmama, demonstra a eficiência da vaca em converter alimento em produto (BRAGA NETTO, 2013), ou seja, a conversão da energia alimentar em peso de bezerro desmamado (JENKINS \& FERRELL, 1992).

Albuquerque et al., (1993) afirmam que o leite materno é responsável por uma porção significativa (de 20 a 25\%) da variação no peso à desmama e no ganho de peso do nascimento à desmama. Sinclair et al. (1998) sugerem que a maioria das vacas de raças produtoras de carne mobilizagrandes quantidades de reservas corporais para sustentar a produção de leite.

Por outro lado, alguns resultados indicam que o potencial de crescimento do bezerro não é uma variável tão dependente da produção de leite das vacas. Possivelmente, um alto potencial de crescimento dos bezerros pode ser compensado com maior consumo de forragem para satisfazer suas demandas nutricionais do crescimento extra quando sua mãe não possui produção de leite compatível (GRINGS et al., 1996). 
FREIRIA, L.B. et al. Exigências nutricionais e eficiência energética para vacas de corte. PUBVET, Londrina, V. 8, N. 9, Ed. 258, Art. 1714, Maio, 2014.

Braga Neto (2013), na definição de prioridade de utilização energética, sugere que vacas com alto potencial de crescimento e relativamente baixo potencial para produção de leite priorizam o crescimento a expensas da produção leiteira. Por outro lado, aquelas com altos potenciais de produção de leite somente terão suficiente energia para crescimento se seus requerimentos de mantença forem relativamente baixos.

Paulino et al. (2010), na compilação de resultados, apresenta a seguinte equação para predizer produção de Leite, $\mathrm{PL}=5,9579+0,4230 \times \mathrm{S} \times \mathrm{e}^{(-}$ 0,1204xS), sendo $S$, semana de lactação. Henriques et al. (2011), avaliando vacas Nelore primíparas observaram que o pico da lactação ocorreu na oitava semana pós-parto, com estimativa média observada de 7,25 kg/dia, esses animais recebem dieta a base de silagem de milho e concentrado (fubá de milho, farelo de soja e uréia) na proporção 70:30, já Restle et al. (2003), ao trabalharem com vacas Nelore em lactação, consumindo pastagem cultivada, na $12^{a}$ semana de lactação encontraram produção máxima de $5,4 \mathrm{~kg} / \mathrm{dia}$.

Fonseca (2009) determinou a composição média do leite produzido por novilhas Nelore, que apresentou 3,7\% de proteína bruta, 3,88\% de gordura, $4,74 \%$ de lactose e 0,75 Mcal de EL/kg. Restle et al. (2003), encontrou valores superiores, sendo 5,00\% de gordura e 5,14 de lactose.

Desta forma com a utilização de conjuntos de dados, pode se forma estratégias para garantir a desmama de bezerros com adequado peso. Pois considerando energia e proteína como os nutrientes mais limitantes, evidenciase que a partir da 9a semana de vida (Tabela 4), ou seja, por volta dos 63 dias de idade, o leite já não consegue fornecer toda a energia necessária para que o bezerro ganhe em torno de $800 \mathrm{~g} / \mathrm{dia}$ (PAULINO et al., 2010).

O NRC (2000) determinou as exigências de $E L_{m}$ como sendo $77 \mathrm{Kcal} / \mathrm{kg}$ $\mathrm{PC}^{0,75}$, sendo recomendados descontos de $10 \%$ para animais zebuínos e $20 \%$ de acréscimo para vacas em lactação, assim, define o valor de $83,16 \mathrm{Kcal} / \mathrm{kg}$ $P C^{0,75}$ para vacas em lactação. O INRA (1988) fixou as exigências de $E L_{m}$ de

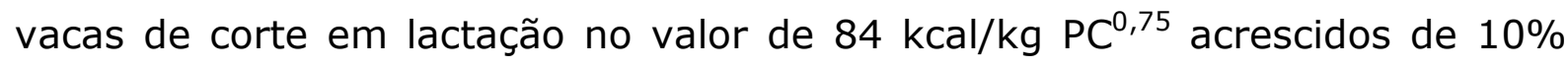
para vacas totalmente confinadas e $20 \%$ quando em pastagens, 92,4 e 100,8 
FREIRIA, L.B. et al. Exigências nutricionais e eficiência energética para vacas de corte. PUBVET, Londrina, V. 8, N. 9, Ed. 258, Art. 1714, Maio, 2014.

$\mathrm{kcal} / \mathrm{kg} P \mathrm{PC}^{0,75}$. Segundo a CSIRO (1980), os requisitos de $E L_{m}$ fixou-se em $66,87 \mathrm{kcal} / \mathrm{PC}^{0,75}$, com multiplicadores de 1,4 para Bostaurus $(93,62$ $\left.\mathrm{kcal} / \mathrm{PC}^{0,75}\right)$ e 1,2 para Bosindicus $\left(80,24 \mathrm{kcal} / \mathrm{PC}^{0,75}\right)$.

Tabela 4 - Produção de leite de vacas Nelore, disponibilidade de EM e PM via leite, exigências de EM e PM totais para mantença e ganho de peso de bezerros Nelore lactentes e necessidade de leite para atender as exigências de EM dos bezerros, de acordo com a semana de lactação e peso dos animais

\begin{tabular}{ccccccc}
\hline SL & $\begin{array}{c}\text { Peso } \\
\text { bezerro }\end{array}$ & $\begin{array}{c}\text { EM via } \\
\text { leite }\end{array}$ & $\begin{array}{c}\text { PM via } \\
\text { leite }\end{array}$ & $\mathrm{EM}_{\mathrm{t}}$ & $\mathrm{PM} \mathrm{t}$ & $\mathrm{NL}$ \\
\hline 1 & 35,60 & 4,63 & 160,71 & 2,91 & 154,87 & 3,98 \\
2 & 41,20 & 4,85 & 168,06 & 3,25 & 156,79 & 4,45 \\
3 & 46,80 & 5,01 & 173,63 & 3,58 & 158,65 & 4,89 \\
4 & 52,40 & 5,12 & 177,72 & 3,90 & 160,49 & 5,32 \\
5 & 58,00 & 5,21 & 180,59 & 4,20 & 162,29 & 5,75 \\
6 & 63,60 & 5,26 & 182,46 & 4,50 & 164,09 & 6,16 \\
7 & 69,20 & 5,29 & 183,54 & 4,80 & 165,87 & 6,56 \\
8 & 74,80 & 5,30 & 183,97 & 5,09 & 167,66 & 6,95 \\
9 & 80,40 & 5,30 & 183,88 & 5,37 & 169,44 & 7,34 \\
10 & 86,00 & 5,29 & 183,39 & 5,65 & 171,23 & 7,72 \\
15 & 114,00 & 5,12 & 177,65 & 6,98 & 180,34 & 8,09 \\
\hline
\end{tabular}

$\mathrm{SL}$ = semana de lactacao; peso do bezerro em $\mathrm{kg}$ : considerou-se peso ao nascimento de $30 \mathrm{~kg}$ e GMD de $0,8 \mathrm{~kg} / \mathrm{dia} ; \mathrm{EM}$ via leite: quantidade de energia metabolizavel disponibilizada ao bezerro via leite (Mcal/dia); PM via leite: quantidade de proteinametabolizavel disponibilizada ao bezerro via leite ( $\mathrm{g} / \mathrm{dia})$; $\mathrm{EMt}=$ exigencias totais (mantenca + ganho de peso) de energia metabolizavel do bezerro; PMt: exigencias totais (mantenca + ganho de peso) de proteinametabolizavel do bezerro; NL: necessidade de leite $(\mathrm{kg} / \mathrm{dia})$ para atender as exigencias totais de EM do bezerro. Adaptado por PAULINO et al. (2010).

Já o sistema BR-CORTE, descrito por Paulino et al. (2010), ao utilizarem a equação $P C=97,84 e^{0,0024}$. CEM $(P C$, produção de calor e CEM, consumo de energia metabolizável), quando o CEM é igualado a zero, equivale a produção de calor em jejum, ou seja, as exigências liquidas de energia para mantença, o que define um valor $97,84 \mathrm{Kcal} / \mathrm{PCVZ}^{0,75}$ que corresponde a $90 \mathrm{Kcal} / \mathrm{PC}^{0,75}$. Valor próximo ao recomendado por Valadares Filho et al. (2006), de 86,76 $\mathrm{Kcal} / \mathrm{PC}^{0,75}$ (1,2 x 72,3; fator de correção para vacas lactantes).

Paulino et al. (2010), também determina a quantidade de EM para mantença, sendo o valor de $140,17 \mathrm{Kcal} / \mathrm{PCVZ}^{0,75}$, valor obtido pela seguinte equação ER (Kcal/PCVZ0,75) = 61,958 - 0,442 CEM (Kcal/PCVZ0,75), em energia retida é zero, o que resulta numa eficiência de utilização de energia 
FREIRIA, L.B. et al. Exigências nutricionais e eficiência energética para vacas de corte. PUBVET, Londrina, V. 8, N. 9, Ed. 258, Art. 1714, Maio, 2014.

metabolizável para mantença $\left(k_{m}\right)$ no valor de $0,70(97,84 / 140,17)$, e para ganho 0,44 , o que equivale a inclinação da reta. Assim na tabela 5 descreve os valores de $\mathrm{EL}_{\mathrm{m}}$ no sistema de BR CORTE (2010), NRC (2000) e BR CORTE (2006), e na tabela 6. descreve os valores para energia de mantença descrita por Paulino et al. (2010).

O sistema BR CORTE (2010), para definir as exigências de energia liquida para ganho de peso de vacas Nelore lactantes, se utilizou a equação descrita por Fonseca (2009), (cujos coeficientes a e b foram, respectivamente, 0,8133 e 1 ,2389) em que $E R=a \times b \times P C V Z{ }^{b-1} \times$ GPCVZ. Sendo apresentados na tabela 7.

Tabela 5 - Exigências de $E L_{m}$ (Mcal/dia) de vacas Nelore lactantes em função do peso corporal

\begin{tabular}{|c|c|c|c|c|c|}
\hline PC & BR CORTE $^{1}$ & $\mathrm{NRC}^{2}$ & BR CORTE $^{3}$ & CSIRO $^{4}$ & INRA $^{5}$ \\
\hline 300 & 6,50 & 6,00 & 6,25 & 5,78 & 7,26 \\
\hline 350 & 7,29 & 6,73 & 7,02 & 6,50 & 8,15 \\
\hline 400 & 8,07 & 7,43 & 7,76 & 7,17 & 9,01 \\
\hline 450 & 8,81 & 8,12 & 8,50 & 7,84 & 9,48 \\
\hline
\end{tabular}

Tabela 6 - Exigências de energia para mantença de vacas Nelore lactantes em função do peso corporal

\begin{tabular}{cccc}
\hline $\mathrm{PC}$ & $\mathrm{EM}_{\mathrm{m}}$ (Mcal/dia) & $\mathrm{EL}_{\mathrm{m}}$ (Mcal/dia) & $\mathrm{NDT}(\mathrm{Kg} / \mathrm{dia})$ \\
\hline 300 & 9,29 & 6,50 & 2,57 \\
350 & 10,42 & 7,29 & 2,88 \\
400 & 11,53 & 8,07 & 3,19 \\
450 & 12,59 & 8,81 & 3,48 \\
\hline
\end{tabular}

$\mathrm{EL}_{\mathrm{m}}=97,84 \mathrm{Kcal} / \mathrm{PCVZ}^{0,75}, \mathrm{EM}_{\mathrm{m}}=140,17 \mathrm{Kcal} / \mathrm{PCVZ}^{0,75} ; \mathrm{PCVZ} / \mathrm{PC}=0,894 ; \mathrm{K}_{\mathrm{m}}=0,70 ; \mathrm{PC}=$ peso corporal $\mathrm{EM}_{\mathrm{m}}=$ energia metabolizável para mantença; $\mathrm{EL}_{\mathrm{m}}=$ energia liquida de mantença; $\mathrm{NDT}=$ nutrientes digestíveis totais. $\mathrm{NDT}=\left(\mathrm{EM}_{\mathrm{m}} / 0,82\right) / 4,409$. Adaptado de Paulino et al. (2010).

Em relação à energia requerida para lactação, o sistema BR CORTE, definido por Paulino et al. (2010), descreve que as exigências de energia metabolizável (EM) para lactação foram calculadas ao considerar o valor médio 
FREIRIA, L.B. et al. Exigências nutricionais e eficiência energética para vacas de corte. PUBVET, Londrina, V. 8, N. 9, Ed. 258, Art. 1714, Maio, 2014.

de energia líquida obtido por $\mathrm{kg}$ de leite de vacas Nelore $(0,75 \mathrm{Mcal}$ de energia liquida/kg), sendo dividido pela eficiência utilização da EM para lactação, valor de 0,70, o mesmo da eficiência utilização $\mathrm{EM}_{\mathrm{m}}$, recomendado pelo NRC (2001). Assim são necessários 1,07 Mcal de EM/kg de leite produzido, ou seja, 0,295 $\mathrm{kg}$ de $\mathrm{NDT} / \mathrm{kg}$ de leite$(\mathrm{NDT}=(\mathrm{EM} / 0,82) / 4,409)$.

Tabela 7 - Exigências de energia para ganho de um quilograma de peso corporal de vacas Nelore lactantes

\begin{tabular}{|c|c|c|c|}
\hline \multirow{2}{*}{ Peso corporal } & \multicolumn{3}{|c|}{ Exigências $^{1}$} \\
\hline & $\mathrm{EL}_{q}$ (Mcal/dia) & $\mathrm{EM}_{\mathrm{q}}$ (Mcal/dia) & NDT $(\mathrm{Kg} / \mathrm{dia})$ \\
\hline 300 & 3,58 & 8,14 & 2,25 \\
\hline 350 & 3,72 & 8,45 & 2,34 \\
\hline 400 & 3,84 & 8,73 & 2,41 \\
\hline 450 & 3,95 & 8,98 & 2,48 \\
\hline
\end{tabular}

Conforme o preconizado pelo NRC (2001) corrige-se o teor de gordura do leite para 4\%, utilizando a equação Energia (Mcal $/ \mathrm{kg})=0,0929 \times \mathrm{G}(\%)+$ 0,0547 x PB (\%) + 0,0395 x Lactose (\%), gera um valor de 0,76 Mcal/kg de leite, com substituição dos teores apresentados por Fonseca (2009). Com esse valor energia por $\mathrm{kg}$ de leite, apresenta uma exigência EM para lactação de $1,09 \mathrm{Mcal} / \mathrm{kg}$ de leite, o que corresponde a 0,30 kg de NDT/ $\mathrm{kg}$ de leite (PAULINO et al., 2010).

Neste sentindo, a exigência de uma vaca Nelore de $400 \mathrm{~kg}$ de PC, produzindo, em média, 5,4 kg de leite/dia, com ganho de $1 \mathrm{~kg}$ de $\mathrm{PC} / \mathrm{dia}$, os requerimentos energéticos desse animal seriam de 8,05 Mcal/dia (97,84 $\left.x(0,894 \times 400)^{0,75} / 1000\right)$ para $E L_{m}$ e de $11,5 \mathrm{Mcal} /$ dia de $\mathrm{EM}_{\mathrm{m}}(8,05 / 0,70)$. As exigências de NDT para mantença seria de $3,18 \mathrm{~kg}$ de NDT/dia $(11,5 / 0,82 / 4,409)$. As exigências de energia liquida para ganho de $1 \mathrm{~kg}$ de peso corporal seriam 3,84 Mcal $\left(0,8133 \times 1,2389 \times(400.0,894)^{0,2389} \times 0,936\right)$, equivalentes a $2,41 \mathrm{~kg}$ de NDT. 
FREIRIA, L.B. et al. Exigências nutricionais e eficiência energética para vacas de corte. PUBVET, Londrina, V. 8, N. 9, Ed. 258, Art. 1714, Maio, 2014.

As exigências de EM para lactação (considerando um leite com $4 \%$ de gordura) seriam de 5,88 Mcal/dia $(0,76 / 0,7=1,09 \times 5,4 \mathrm{~kg})$, o que seria equivalente a $1,62 \mathrm{~kg} \mathrm{NDT} / \mathrm{dia}(0,30 \times 5,4 \mathrm{~kg})$. Portanto, as exigências totais de NDT para essa vaca seriam de $8,64 \mathrm{~kg}$ de NDT.

Nas tabelas 8,9 e 10, demonstram a exigências de energia de vacas de corte lactantes, em função do ganho de peso $(\mathrm{kg} / \mathrm{dia})$ e produção de leite ( $\mathrm{kg} / \mathrm{dia})$.

\section{EXIGÊNCIA DE PROTEÍNA PARA VACAS DE CORTE LACTANTES}

As exigências de proteína metabolizável de mantença proposta por Valadares filho et al. (2006), na primeira edição do sistema BR-CORTE, foi o valor de $4,0 \mathrm{~g} / \mathrm{PC}^{0,75}$, correlacionando o nitrogênio retido e o nitrogênio absorvido, sem encontrar diferenças entres as classes sexuais, valor próximo do NRC (2000), que é de $3,8 \mathrm{~g} / \mathrm{PC}^{0,75}$.

Tabela 8 - Exigências nutricionais de EM; EL e de NDT para vacas de diferentes de peso corporais com diferentes produções leiteiras, para GMD $(1 \mathrm{~kg})$ somado a mantença.

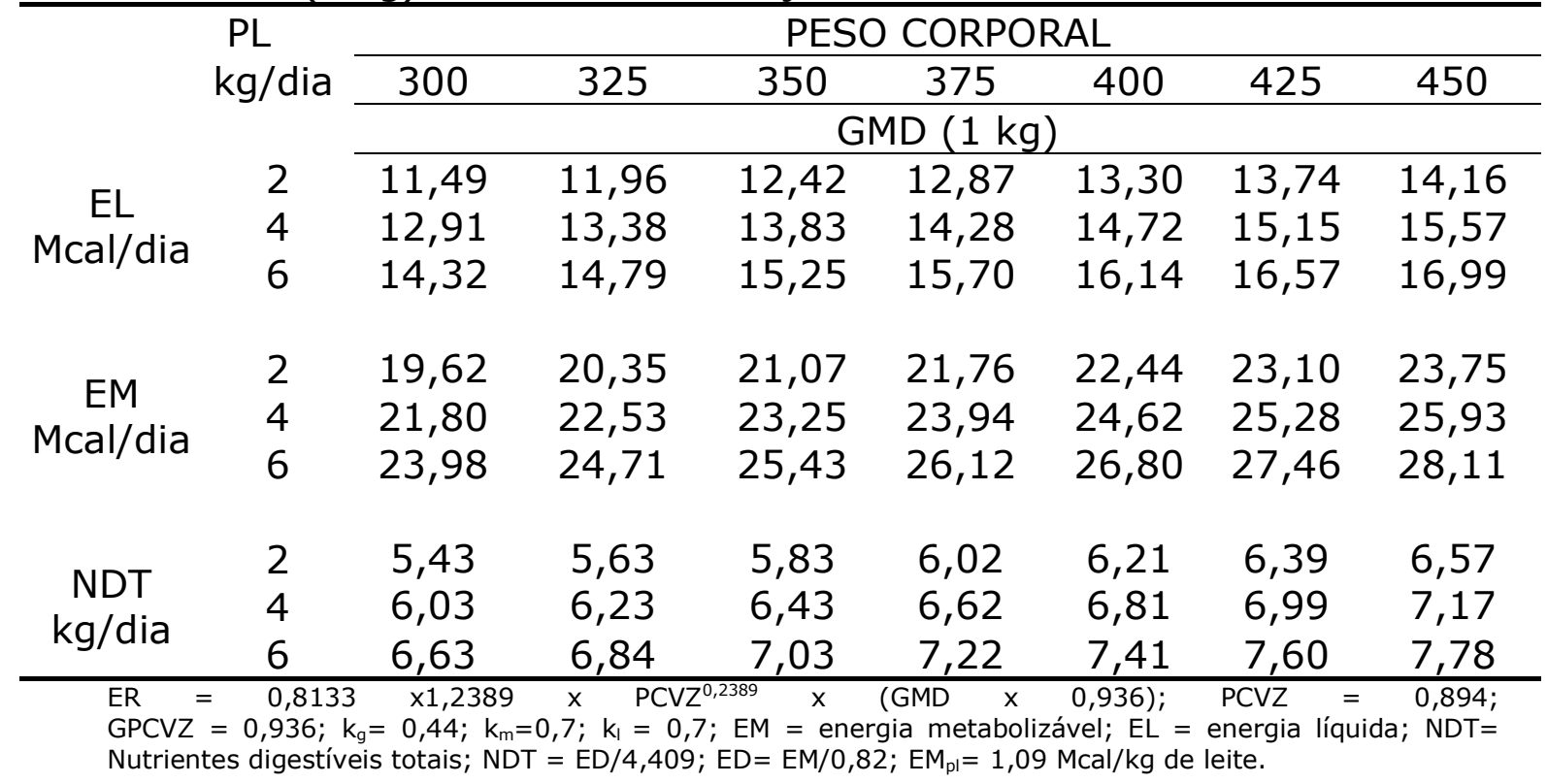


FREIRIA, L.B. et al. Exigências nutricionais e eficiência energética para vacas de corte. PUBVET, Londrina, V. 8, N. 9, Ed. 258, Art. 1714, Maio, 2014.

Na segunda edição do BR-CORTE, Marcondes et al. (2010), ao avaliar os requerimentos de $\mathrm{PM}_{\mathrm{m}}$, obteve o valor de 3,71g/PC, 0 , ao considerar o valor médio entre o consumo $\mathrm{PM}_{\mathrm{m}}$ correlacionado com GMD e o consumo $\mathrm{PM}_{\mathrm{m}}$ correlacionado com GPCVZ, mas preconizou o utilizado de $4,0 \mathrm{~g} / \mathrm{PC}^{0,75}$ pela primeira versão. Esse autor propos para animais em regime à pasto possuem um exigência de $\mathrm{PM}_{\mathrm{m}}, 12,3 \%$ maior que animais confiandos, ou seja, $4,5 \mathrm{~g} / \mathrm{PC}^{0,74}$.

Para exigências líquidas de proteína para ganho de peso de vacas Nelore, o sistema BR-CORTE preconizou a seguinte equação, $P R=a \times b \times P C V Z^{b-1} \times$ GPCVZ, sendo $a=0,4612, b=0,8161, P C V Z=0,894 \times$ PC e GPCVZ $=0,936 \times$ GPC. Para requerimentos de $\mathrm{PM}_{g}$, foi proposto a seguinte equação $P M_{g}=P R / k$, o valor de $\mathrm{k}$ (eficiência) se define para vacas com $P C V Z<300 \mathrm{~kg}$ o valor de 0,53 e para vacas com PCVZ $\geq 300 \mathrm{~kg}$ o valor de 0,49 , orientações do NRC (2000).

Tabela 9 - Exigências nutricionais de EM; EL e de NDT para vacas de diferentes de peso corporais com diferentes produções leiteiras, para $\operatorname{GMD}(0,5 \mathrm{~kg})$ somado a mantença.

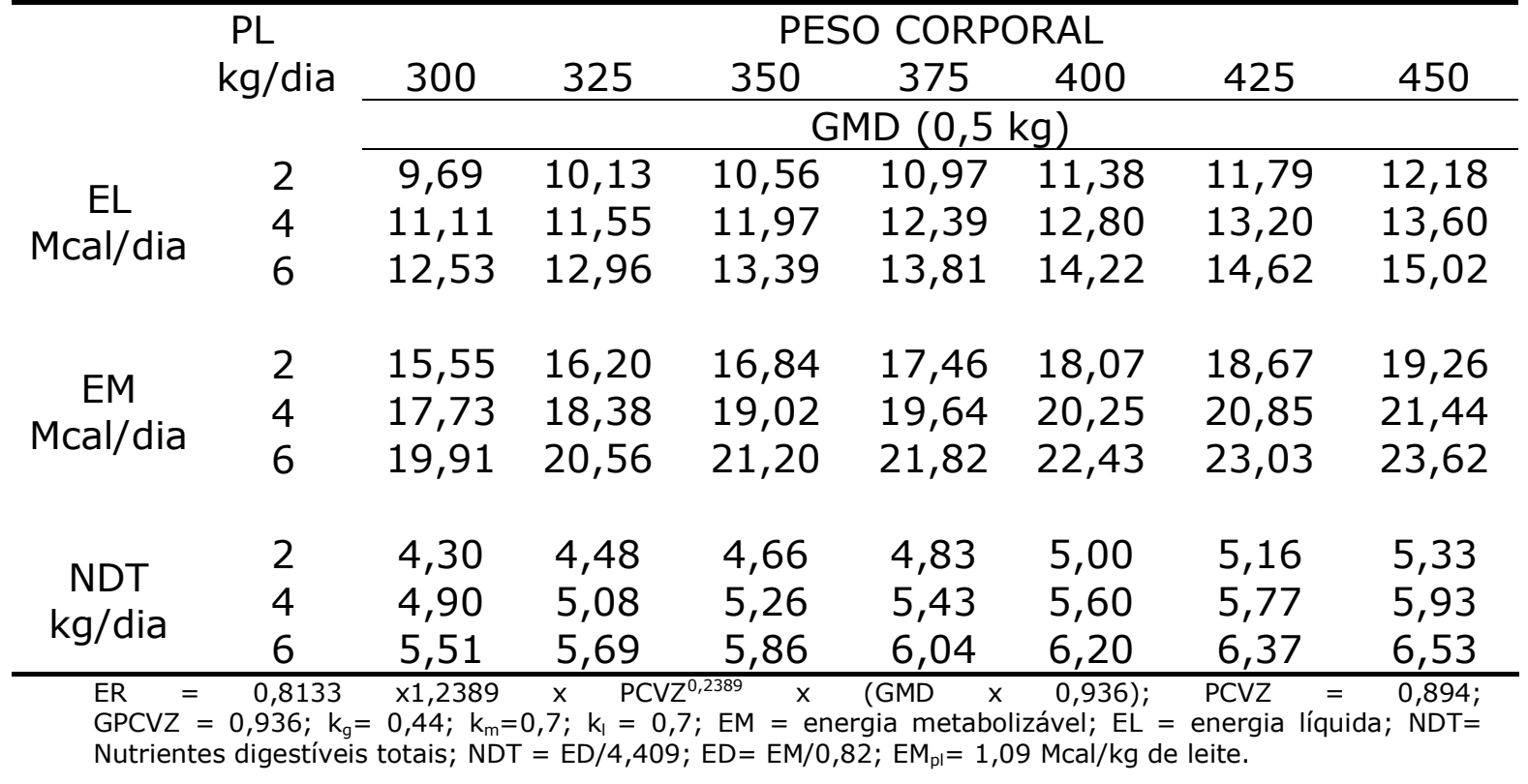


FREIRIA, L.B. et al. Exigências nutricionais e eficiência energética para vacas de corte. PUBVET, Londrina, V. 8, N. 9, Ed. 258, Art. 1714, Maio, 2014.

Tabela 10 - Exigências nutricionais de EM; EL e de NDT para vacas de diferentes de peso corporais com diferentes produções leiteiras, para mantença.

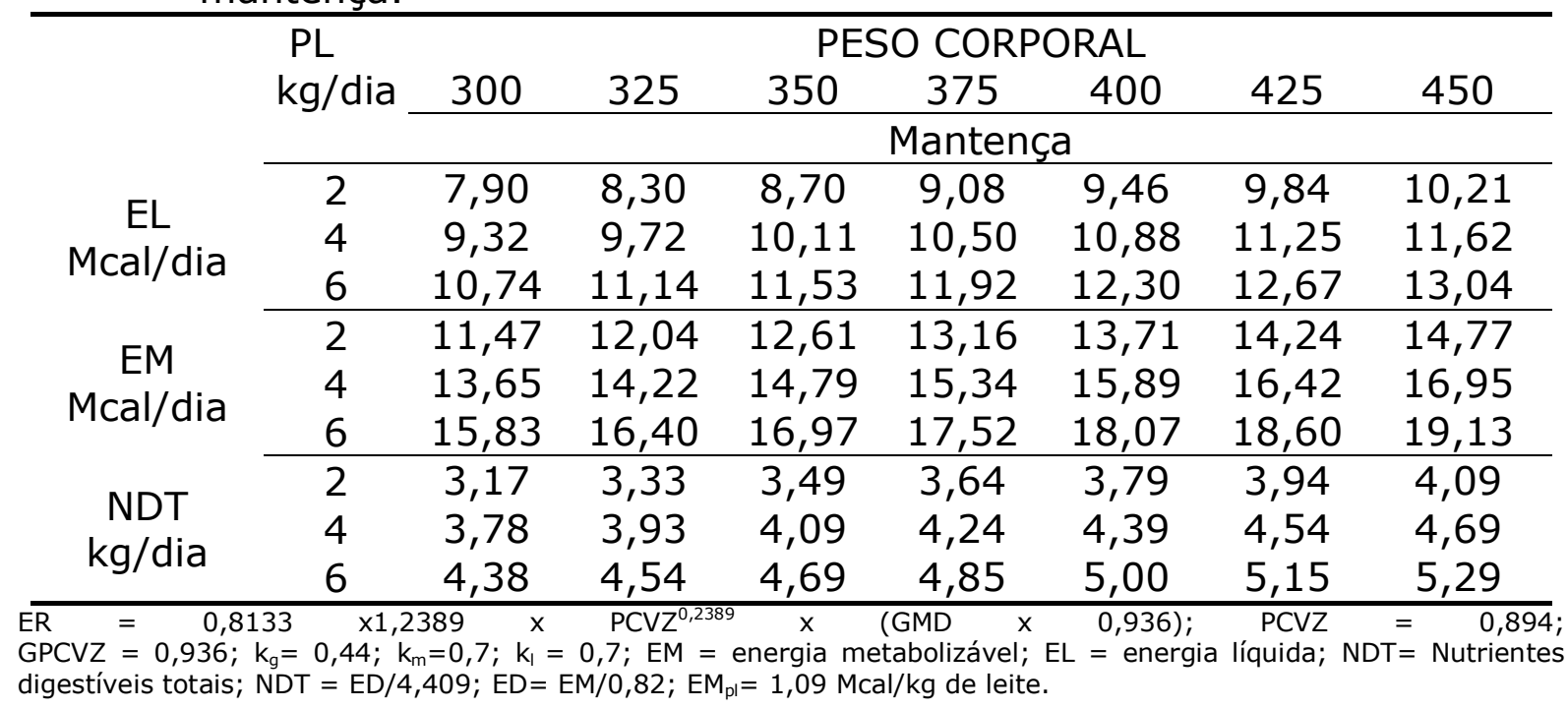

Para o calculo de exigência de proteína bruta, se utiliza PB=PDR+PNDR. A primeira versão BR-CORTE, sugere que a produção de proteína bruta microbiana (PBmic) é calculada ao considerar a síntese microbiana de $120 \mathrm{~g} / \mathrm{kg}$ de NDT, assim PDR (proteína degradável no rúmen) = 1,11 x PBmic, ou seja, $\operatorname{PDR}=1,11 \times 120 \times$ exigências totais de NDT $(\mathrm{kg} / \mathrm{dia})$ e PNDR (proteína não degradável no rúmen $)=($ PMtotal - PBmic $\times 0,64) / 0,8$ ) (Valadares et al., 2006). Paulino et al. (2010) encontra-se valor de 52,8 g de PM/kg de leite produzido que é a exigência destes animais em lactação.

Tabela 11 apresenta exigências diárias de proteína para vacas Nelore lactantes, em função do ganho de peso, e as tabelas 12 e 13 apresentam as exigências diárias de proteína em função do ganho de peso, tamanho corporal e produção de leite. Já tabela 14 apresenta exigências diárias de proteína em função produção de leite e mantença. 
FREIRIA, L.B. et al. Exigências nutricionais e eficiência energética para vacas de corte.

PUBVET, Londrina, V. 8, N. 9, Ed. 258, Art. 1714, Maio, 2014.

Tabela 11 - Exigências diárias de proteína para vacas Nelore lactantes.

\begin{tabular}{|c|c|c|c|c|c|c|c|c|}
\hline$P C$ & GPC & $\mathrm{PM}_{\mathrm{m}}(\mathrm{g})$ & PR & $\mathrm{PM}_{\mathrm{q}}(\mathrm{g})$ & $\mathrm{PM}_{\mathrm{t}}(\mathrm{g})$ & $\operatorname{PDR}(g)$ & PNDR(g) & $\mathrm{PB}(\mathrm{g})$ \\
\hline \multirow{4}{*}{300} & 0,25 & \multirow{4}{*}{288,34} & 31,50 & 53,43 & 347,77 & 416,92 & 134,23 & 551,15 \\
\hline & 0,50 & & 63,00 & 118,87 & 407,21 & 492,84 & 153,81 & 646,65 \\
\hline & 0,75 & & 94,50 & 178,30 & 466,64 & 567,43 & 174,34 & 741,77 \\
\hline & 1,00 & & 126,00 & 237,74 & 526,08 & 642,02 & 194,88 & 836,90 \\
\hline \multirow{4}{*}{350} & 0,25 & \multirow{4}{*}{323,68} & 30,62 & 62,49 & 386,16 & 462,20 & 149,58 & 611,78 \\
\hline & 0,50 & & 61,23 & 124,96 & 448,64 & 539,46 & 172,00 & 711,46 \\
\hline & 0,75 & & 91,85 & 187,45 & 511,12 & 618,05 & 193,46 & 811,51 \\
\hline & 1,00 & & 122,46 & 249,92 & 573,60 & 695,30 & 215,88 & 911,18 \\
\hline \multirow{4}{*}{400} & 0,25 & \multirow{4}{*}{357,77} & 29,87 & 60,96 & 418,74 & 504,83 & 159,59 & 664,42 \\
\hline & 0,50 & & 59,75 & 121,94 & 479,70 & 586,08 & 177,23 & 763,31 \\
\hline & 0,75 & & 89,62 & 182,90 & 540,67 & 666,00 & 193,84 & 859,84 \\
\hline & 1,00 & & 119,42 & 243,86 & 601,63 & 745,92 & 214,44 & 960,36 \\
\hline \multirow{4}{*}{450} & 0,25 & \multirow{4}{*}{390,81} & 29,23 & 59,65 & 450,47 & 546,12 & 169,49 & 715,61 \\
\hline & 0,50 & & 58,47 & 119,33 & 510,13 & 628,70 & 184,54 & 813,24 \\
\hline & 0,75 & & 87,70 & 178,98 & 569,79 & 711,29 & 199,60 & 910,89 \\
\hline & 1,00 & & 116,93 & 238,63 & 629,45 & 793,87 & 214,65 & 1008,52 \\
\hline
\end{tabular}


FREIRIA, L.B. et al. Exigências nutricionais e eficiência energética para vacas de corte. PUBVET, Londrina, V. 8, N. 9, Ed. 258, Art. 1714, Maio, 2014.

Tabela 12 - Exigências diárias de PMt, PDR, PNDR, PB para vacas Nelore lactantescom diferentes produções leiteiras e pesos corporais, para ganho médio de 0,5 $\mathrm{kg}+$ mantença.

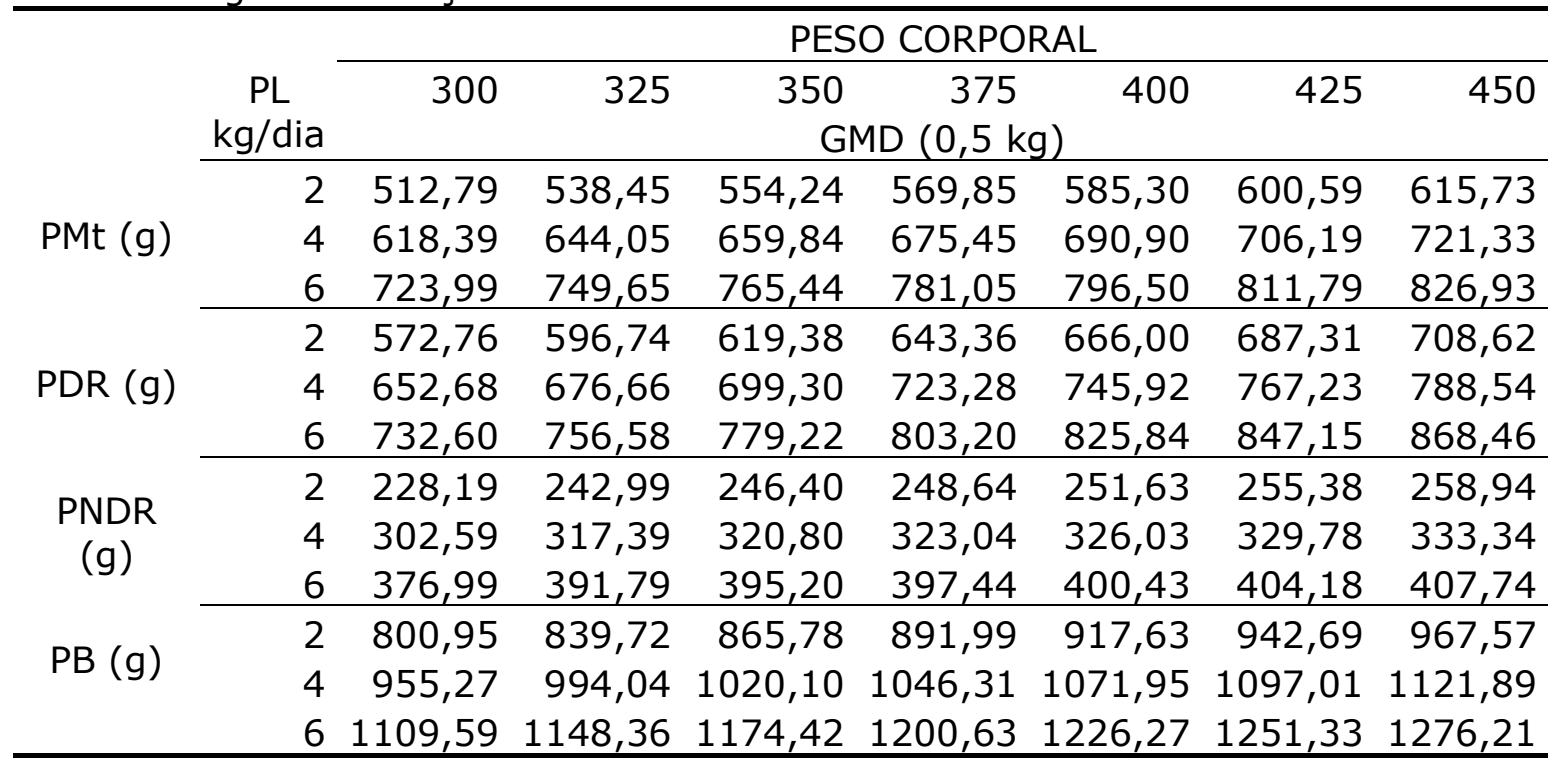

$\mathrm{PRg}=\mathrm{a} \times \mathrm{b} \times \mathrm{PCVZ}^{\mathrm{b}-1} \times(\mathrm{GMD} \times \mathrm{GPCVZ} \times 1000)$. Onde: $\mathrm{a}$ e $\mathrm{b}=0,4612$ e 0,8161 respectivamente; PCVZ $=0,894 ; \mathrm{GPCVZ}=$ 0,936; $\mathrm{PM}_{\mathrm{g}}$ (proteína metabolizável para ganho) $=\mathrm{PR}_{\mathrm{g}} / \mathrm{k} . \mathrm{k}=0,53$ para vacas com menos de $300 \mathrm{~kg}$ de $\mathrm{PCVZ}$ e 0,49 para fêmeas com mais de $300 \mathrm{~kg}$ de PCVZ. $\mathrm{PM}_{1}$ (proteína metabolizável para lactação) $=52,8 / \mathrm{kg}$ leite; $P D R_{1}=120 \times$ $\mathrm{NDT}_{1} \times 1,11 ; \mathrm{PNDR}_{\mathrm{l}}=\left(\mathrm{PM}_{\mathrm{l}}-\left(120 \times \mathrm{NDT}_{\mathrm{l}}\right) \times 0,64\right) / 0,8 ; \mathrm{PB}_{\mathrm{l}}=\mathrm{PNDR}_{\mathrm{l}}+\mathrm{PDR}_{\mathrm{l}} ; \mathrm{PM}_{\mathrm{t}}=\mathrm{PM}_{\mathrm{m}}+\mathrm{PM}_{\mathrm{g}}+\mathrm{PM}_{\mathrm{l}} ; \mathrm{PDR}_{\mathrm{t}}=\mathrm{PDR}_{\mathrm{m}}+$ $\mathrm{PDR}_{\mathrm{g}}+\mathrm{PDR}_{\mathrm{l}} ; \mathrm{PNDR}_{\mathrm{t}}=\mathrm{PNDR}_{\mathrm{m}}+\mathrm{PNDR}_{\mathrm{g}}+\mathrm{PNDR}_{\mathrm{l}} ; \mathrm{PBt}=\mathrm{PDR}_{\mathrm{t}}+\mathrm{PNDR}_{\mathrm{t}}$

Tabela 13 - Exigências diárias de PMt, PDR, PNDR, PB para vacas Nelore lactantescom diferentes produções leiteiras e pesos corporais, para ganho médio de $1 \mathrm{~kg}$ + mantença.

\begin{tabular}{crrrrrrrr}
\hline & \multicolumn{7}{c}{ PESO CORPORAL } \\
\cline { 2 - 9 } & $\begin{array}{c}\text { PL } \\
\text { kg/dia }\end{array}$ & 300 & 325 & \multicolumn{7}{c}{350} & $\begin{array}{c}375 \\
\text { GMD }(1 \mathrm{~kg})\end{array}$ \\
\cline { 2 - 9 } PMt (g) & 2 & 631,64 & 665,13 & 679,20 & 693,24 & 707,23 & 721,17 & 735,05 \\
& 4 & 737,24 & 770,73 & 784,80 & 798,84 & 812,83 & 826,77 & 840,65 \\
& 6 & 842,84 & 876,33 & 890,40 & 904,44 & 918,43 & 932,37 & 946,25 \\
PDR & 2 & 721,94 & 749,92 & 775,22 & 801,86 & 825,84 & 851,15 & 875,12 \\
(g) & 4 & 801,86 & 829,84 & 855,14 & 881,78 & 905,76 & 931,07 & 955,04 \\
& 6 & 881,78 & 909,76 & 935,06 & 961,70 & 985,68 & 1010,99 & 1034,96 \\
PNDR & 2 & 269,23 & 290,93 & 290,28 & 288,63 & 288,84 & 288,02 & 288,09 \\
(g) & 4 & 343,63 & 365,33 & 364,68 & 363,03 & 363,24 & 362,42 & 362,49 \\
& 6 & 418,03 & 439,73 & 439,08 & 437,43 & 437,64 & 436,82 & 436,89 \\
\hline & 2 & 991,18 & 1040,85 & 1065,50 & 1090,49 & 1114,68 & 1139,17 & 1163,22 \\
PB (g) & 4 & 1145,50 & 1195,17 & 1219,82 & 1244,81 & 1269,00 & 1293,49 & 1317,54 \\
& 6 & 1299,82 & 1349,49 & 1374,14 & 1399,13 & 1423,32 & 1447,81 & 1471,86 \\
\hline
\end{tabular}

PRg = a xbx PCVZ ${ }^{b-1} \times(G M D \times G P C V Z \times 1000)$. Onde: $a$ e b $=0,4612$ e 0,8161 respectivamente; PCVZ = 0,894; GPCVZ = 0,936; PMg (proteína metabolizável para ganho) $=\mathrm{PR}_{\mathrm{g}} / \mathrm{k} . \mathrm{k}=0,53$ para vacas com menos de $300 \mathrm{~kg}$ de $\mathrm{PCVZ}$ e 0,49 para fêmeas com mais de 300 kg de PCVZ. $\mathrm{PM}_{1}$ (proteína metabolizável para lactação) $=52,8 / \mathrm{kg}$ leite; $\mathrm{PDR}_{1}=120 \times \mathrm{NDT}_{1} \times 1,11 ; \mathrm{PNDR}_{\mathrm{I}}=\left(\mathrm{PM}_{1}-\left(120 \times \mathrm{NDT}_{1}\right) \times\right.$ $0,64) / 0,8 ; \mathrm{PB}_{\mathrm{l}}=\mathrm{PNDR}_{\mathrm{l}}+\mathrm{PDR}_{\mathrm{l}} ; \mathrm{PM}_{\mathrm{t}}=\mathrm{PM}_{\mathrm{m}}+\mathrm{PM}_{\mathrm{g}}+\mathrm{PM}_{\mathrm{l}} ; \mathrm{PDR}_{\mathrm{t}}=\mathrm{PDR}_{\mathrm{m}}+\mathrm{PDR}_{\mathrm{g}}+\mathrm{PDR}_{\mathrm{l}} ; \mathrm{PNDR}_{\mathrm{t}}=\mathrm{PNDR}_{\mathrm{m}}+\mathrm{PNDR}_{\mathrm{g}}+\mathrm{PNDR}_{\mathrm{l}} ; \mathrm{PBt}^{\mathrm{P}}=\mathrm{PDR}_{\mathrm{t}}+$ PNDR $_{\mathrm{t}}$. 
FREIRIA, L.B. et al. Exigências nutricionais e eficiência energética para vacas de corte. PUBVET, Londrina, V. 8, N. 9, Ed. 258, Art. 1714, Maio, 2014.

Tabela 14 - Tabela de Exigência nutricionais de PM, PDR, PNDR e PB para vacas Nelore lactantes com diferentes pesos corporais e produção leiteira.

\begin{tabular}{|c|c|c|c|c|c|c|c|c|}
\hline & & \multicolumn{7}{|c|}{ PESO CORPORAL } \\
\hline & \multirow{2}{*}{$\begin{array}{c}\mathrm{PL} \\
\mathrm{kg} / \mathrm{dia}\end{array}$} & 300 & 325 & 350 & 375 & 400 & 425 & 450 \\
\hline & & \multicolumn{7}{|c|}{ Mantença + PL } \\
\hline \multirow{3}{*}{ PMt (g) } & 2 & 393,94 & 411,78 & 429,28 & 446,47 & 463,37 & 480,01 & 496,41 \\
\hline & 4 & 499,54 & 517,38 & 534,88 & 552,07 & 568,97 & 585,61 & 602,01 \\
\hline & 6 & 605,14 & 622,98 & 640,48 & 657,67 & 674,57 & 691,21 & 707,61 \\
\hline \multirow{3}{*}{$\begin{array}{l}\text { PDR } \\
(\mathrm{g})\end{array}$} & 2 & 422,24 & 443,56 & 463,54 & 484,85 & 504,83 & 524,81 & 543,46 \\
\hline & 4 & 502,16 & 523,48 & 543,46 & 564,77 & 584,75 & 604,73 & 623,38 \\
\hline & 6 & 582,08 & 603,40 & 623,38 & 644,69 & 664,67 & 684,65 & 703,30 \\
\hline \multirow{3}{*}{$\begin{array}{c}\text { PNDR } \\
(\mathrm{g})\end{array}$} & 2 & 188,10 & 195,04 & 202,52 & 208,64 & 215,37 & 221,78 & 228,84 \\
\hline & 4 & 262,50 & 269,44 & 276,92 & 283,04 & 289,77 & 296,18 & 303,24 \\
\hline & 6 & 336,90 & 343,84 & 351,32 & 357,44 & 364,17 & 370,58 & 377,64 \\
\hline \multirow{3}{*}{ PB (g) } & 2 & 610,35 & 638,60 & 666,05 & 693,49 & 720,20 & 746,59 & 772,29 \\
\hline & 4 & 764,67 & 792,92 & 820,37 & 847,81 & 874,52 & 900,91 & 926,61 \\
\hline & 6 & 918,99 & 947,24 & 974,69 & 1002,13 & 1028,84 & 1055,23 & 1080,93 \\
\hline
\end{tabular}

\section{IMPLICAÇÕES DO CONHECIMENTO DAS EXIGÊNCIAS NUTRICIONAIS}

Hoffmann (2007) define que alcançar maximização da eficiência de utilização de alimentos é fundamental para sucesso econômico do produtor. Neste sentido as estimativas de requerimentos nutricionais são fundamentas para desenvolvimento de estratégias nutricionais para alcançar um melhor desempenho.

Para vacas gestantes, há uma maior exigência nutricional no período final da gestação, com maior mobilização de nutrientes para o desenvolvimento do feto (Tabela 15), o que tange a atenção no fornecimento de dietas que possam suprir esses requerimentos, sem ocasionar uma depressão no consumo em favor da distensão ruminal, pela competição por espaço interno ocasionado em razão do aumento do feto. 
FREIRIA, L.B. et al. Exigências nutricionais e eficiência energética para vacas de corte. PUBVET, Londrina, V. 8, N. 9, Ed. 258, Art. 1714, Maio, 2014.

Tabela 15 - Exigências nutricionais de vacas Nelore gestantes + mantença.

\begin{tabular}{|c|c|c|c|c|c|c|c|}
\hline & 300 & 325 & 350 & 375 & 400 & 425 & 450 \\
\hline CMS & \multicolumn{7}{|c|}{ CMS 2\% PC } \\
\hline (kg/dia) & 6 & 6,5 & 7 & 7,5 & 8 & 8,5 & 9 \\
\hline \multicolumn{8}{|c|}{ MANTENÇA + GESTAÇÃO } \\
\hline \multicolumn{8}{|l|}{$\begin{array}{l}\text { Dia de } \\
\text { Dastacão }\end{array}$} \\
\hline 130 & 9,38 & 9,09 & 8,83 & 8,61 & 8,41 & 8,22 & 8,05 \\
\hline 160 & 9,54 & 9,24 & 8,98 & 8,74 & 8,53 & 8,34 & 8,16 \\
\hline 190 & 9,83 & 9,51 & 9,22 & 8,97 & 8,75 & 8,54 & 8,35 \\
\hline 220 & 10,31 & 9,95 & 9,64 & 9,36 & 9,11 & 8,88 & 8,68 \\
\hline 250 & 11,10 & 10,68 & 10,31 & 9,99 & 9,70 & 9,44 & 9,20 \\
\hline \multirow[t]{2}{*}{270} & 12,33 & 11,81 & 11,36 & 10,97 & 70,62 & 10,30 & 10,02 \\
\hline & \multicolumn{7}{|c|}{ NDT ( $\%$ dieta) } \\
\hline 130 & 44,63 & 43,64 & 42,75 & 41,95 & 41,21 & 40,53 & 39,90 \\
\hline 160 & 46,33 & 45,21 & 44,21 & 43,31 & 42,48 & 41,73 & 41,03 \\
\hline 190 & 49,27 & 47,92 & 46,73 & 45,65 & 44,68 & 43,80 & 42,99 \\
\hline 220 & 54,03 & 52,32 & 50,81 & 49,46 & 48,25 & 47,16 & 46,16 \\
\hline 250 & 61,24 & 58,98 & 56,99 & 55,23 & 53,66 & 52,25 & 50,97 \\
\hline 270 & 71,41 & 68,36 & 65,71 & 63,37 & 61,29 & 59,43 & 57,75 \\
\hline \multicolumn{8}{|c|}{ 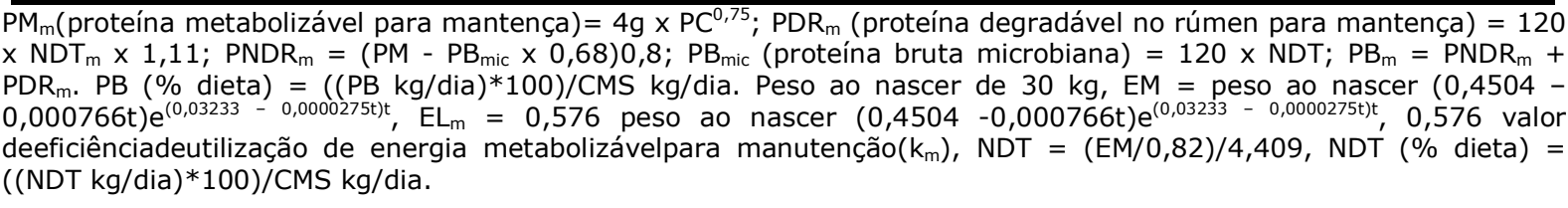 } \\
\hline
\end{tabular}

Para vacas de corte lactantes, na tabela 16, demonstra as exigências de vacas Nelore no pico de lactação (5,4 kg de leite/dia) (RESTLE et al., 2003), e GMD de $1 \mathrm{~kg}$, com CMS de $2 \%$ do PC conforme o descrito para vacas em condições de pastejo por Sarmento (2003).

O que implica no não suprimento das necessidades nutricionais em situações de pastejo, uma vez que se exige grande densidade energética e proteica na dieta, e até mesmo ultrapassando 100\% de NDT. Assim, as matrizes devem estar bem nutridas antes da estação de monta, e após a parição, podendo ser utilizado uma suplementação energética proteica, se esses animais se mantiverem a pasto, para não ocasionar a perda de peso no período de lactação, em consequência subnutrição de sua prole. 
FREIRIA, L.B. et al. Exigências nutricionais e eficiência energética para vacas de corte. PUBVET, Londrina, V. 8, N. 9, Ed. 258, Art. 1714, Maio, 2014.

Tabela 16 - Tabela dos requerimentos de PB e NDT para vacas Nelore lactantes, produção leiteira considerada de $5,4 \mathrm{~kg}$. Concentração da PB e NDT na dieta para que alcance o GMD de 1 e $0,5 \mathrm{~kg}$ ou mantença.

\begin{tabular}{|c|c|c|c|c|c|c|c|}
\hline & 300 & 325 & 350 & 375 & 400 & 425 & 450 \\
\hline \multicolumn{8}{|c|}{ CMS $2 \%$ PC } \\
\hline CMS (kg/dia) & 6 & 6,5 & 7 & 7,5 & 8 & 8,5 & 9 \\
\hline \multicolumn{8}{|c|}{ MANTENÇA } \\
\hline PB (g/dia) & 872,69 & 900,94 & 928,40 & 955,83 & 982,55 & 1008,93 & 1034,64 \\
\hline PB (\% dieta) & 14,54 & 13,86 & 13,26 & 12,74 & 12,28 & 11,87 & 11,50 \\
\hline NDT (kg/dia) & 4,20 & 4,36 & 4,51 & 4,67 & 4,82 & 4,96 & 5,11 \\
\hline NDT ( $\%$ dieta) & 69,96 & 67,02 & 64,46 & 62,21 & 60,20 & 58,41 & 56,79 \\
\hline \multicolumn{8}{|c|}{$\operatorname{GMD}(0,5 \mathrm{KG})$} \\
\hline PB (g/dia) & 1063,29 & 1102,07 & 1128,12 & 1154,34 & 1179,97 & 1205,04 & 1229,91 \\
\hline PB (\% dieta) & 17,72 & 16,95 & 16,12 & 15,39 & 14,75 & 14,18 & 13,67 \\
\hline NDT (kg/dia) & 5,32 & 5,51 & 5,68 & 5,85 & 6,02 & 6,19 & 6,35 \\
\hline NDT ( $\%$ dieta) & 88,75 & 84,70 & 81,17 & 78,06 & 75,30 & 72,82 & 70,59 \\
\hline \multicolumn{8}{|c|}{ GMD (1 KG) } \\
\hline PB (g/dia) & 1253,52 & 1303,19 & 1327,85 & 1352,84 & 1377,02 & 1401,52 & 1425,56 \\
\hline PB (\% dieta) & 20,89 & 20,05 & 18,97 & 18,04 & 17,21 & 16,49 & 15,84 \\
\hline NDT (kg/dia) & 6,45 & 6,65 & 6,85 & 7,04 & 7,23 & 7,42 & 7,59 \\
\hline NDT (\% dieta) & 108 & 102 & 98 & 94 & 90 & 87 & 84 \\
\hline
\end{tabular}

\section{CONSIDERAÇÕES FINAIS}

Ao conhecer os períodos de maior exigência de vacas de corte, torna-se necessário um planejamento de oferta de alimento para atender suas demandas energéticas, principalmente após cinco meses de amamentação, em que o bezerro fica mais independente do leite materno, o que facilita a vaca recuperarsua condição corporal e suprir a demanda de nutrientes do seu feto. $\mathrm{E}$, é válido ressaltar, que é indispensável à suplementação alimentar para a vaca em todas as fases, reprodução, gestação e lactação, para assegurar uma melhor condição corporal da matriz de forma que mantenha produtiva. 


\section{REFERÊNCIAS BIBLIOGRÁFICAS}

ABIEC. Pecuária Brasileira. 2011, disponível em:<http://www.abiec.com.br/3_pecuaria.asp> Acesso em: 23/05/2013.

ABRAHÃO, A. R.; SERRA, L. B.; FERREIRA, S. F.; MUNARI, D. P. Avaliação do peso ao nascer em diferentes agrupamentos genéticos de bovinos de corte. In: Simpósio Brasileiro de Melhoramento Animal, 3, 2000. Anais... Disponível em: <http://sbmaonline.org.br/anais/iii/trabalhos/> Acesso em: 23 maio 2013.

ACNB. Raça, 2013. Disponível em: <http://www.nelore.org.br/Raca> Acesso em 24/05/2013.

AGRICULTURAL AND FOOD RESEARCH COUNCIL. Nutrient Requirements of Ruminant Animals: Energy. Nutr. Abstr. Rev. Ser. B,v.60, p.729-804, 1990.

ALBUQUERQUE, L.G., ELER, J.P., COSTA, M.R.P. et al. Produção de Leite e desempenho do Bezerro na fase de Aleitamento em três raças bovinas de corte. Revista Brasileira deZootecnia, v.22, n.5, p.745-754, 1993.

ALENCAR, M. M. (2004) Utilização de cruzamentos industriais na pecuária de corte tropical. In: SANTOS, F. A. P.; MOURA, J. C.; FARIA, V. P. (eds), Pecuária de Corte Intensiva nos Trópicos, Anais... FEALQ, Piracicaba, SP, p.149-171.

ALENCAR, M. M. de; TULLIO, R. R.; CORRÊA, L. de A. Pesos e relações de peso de bezerros filhos de v/acas nelore e cruzadas com Canchim x Nelore. RevistaBrasileira de Zootecnia, v. 28, n. 5, p. 968-973, 1999.

ANDERSEN, H.; PLUM, M. Gestation length and birth weight in cattle and buffaloes: A review. JournalofDairy Science, v.48, p.1224-1235, 1965.

BASSETT, J. M. Current perspectives on placental development and its integration with fetal growth.ProceedingsofrheNurririonSociery, v.50, p. 311-319, 1991.

BAUMANN, T. A.; LARDY, G. P.; CATON, J. S.; ANDERSON, V. L. Effect of energy source and ruminally degradable protein addition on performance of lactating beef cows and digestion characteristics of steers. Journalof Animal Science, v. 82, p.2667-2678, 2004.

BEAL, W. E.; NOTTER, D. R.; AKERS, R. M. Techniques for estimation of milk yield in beef cows and relationships of milk yield to calf weight gain and postpartum reproduction. Journalof Animal Science, v. 68, p. 937-943, 1990.

BOCCHI, A. L.; TEIXEIRA, R. A.; ALBUQUERQUE, L. G. de. Idade da vaca e mês de nascimento sobre $O$ peso ao desmame de bezerros nelore nas diferentes regiões brasileiras. ActaScientiarum. Animal Sciences, v. 26, no. 4, p. 475-482, 2004

BOTTJE, W.G.; CARSTENS, G.E. Association of mitochondrial function and feed efficiency in poultry and livestock species.Journalof Animal Science, n.87, p.48-63, 2009.

BRAGA NETO, A. L. Eficiência nutricional de vacas de corte sob pastejo. Campo Grande, SP:UFMS,2013. 56p. Dissertação (Mestre em Ciência Animal) - Universidade Federal de Mato Grosso do Sul, 2013. 
COMMONWEALTH SCIENTIFIC AND INDUSTYRIAL RESEARCH ORGANIZATION - CSIRO (1980) Feeding standards for Australian livestock - ruminants. Victoria: AustraliaagriculturalCouncil, 266p.

CUBAS, A. C.; PEROTTO, D.; ABRAHÃO, J. J. dos S.; MELLA, S. C. Desempenho até a desmama de bezerros Nelore e cruzas com Nelore. Revista Brasileira de Zootecnia, v. 30, n. 3, p. 694-701, 2001.

FERREL, C. L.; JENKINS, T. G. Cowtypeandthenutritionalenvironment: nutritionalaspects. Journalof Animal Science, v. 61, n. 3, p.725-74, 1985.

FERRELL, C. L.; GARRETT, W. N.; HINMAN, N. ; GRICHTING, G. Energy utilization by pregnant and nonpregnant heifers. Journal Animal Science, 42:937-950, 1976.

FERRELL, C.L. Maternal and fetal influences on uterine and conceptus development in the cow.I. Growthoftissuesofthegraviduterus. Journal Animal Science, v. 69, p.1945- 1953, 1991.

FONSECA, M. A. Exigências nutricionais de vacas e bezerros Nelore, do Nascimento a desmama. Viçosa, MG: UFV, 2009. 87p. dissertação (mestrado em zootecnia) - Universidade Federal de Viçosa, 2009.

FONSECA, M. A.; VALADARES FILHO, S. C.; HENRIQUES, L. T.; PAULINO, P. V. R.; DETMANN, E.; BENEDETI, P. B.; SILVA, L. D.; AMARAL P. M. Exigências nutricionais de vacas Nelores primíparas lactantes. Revista Brasileira de Zootecnia, v.41, n.5, p.1222-1230, 2012.

GRINGS, E.E.; SHORT, R. E.; MACNEIL,M. D.; HAFERKAMP, M. R.; ADAMS, D. C. Efficiency of production in cattle of two growth potentials on northern great plains rangelands during spring-summer grazing. Journalof Animal Science, v.74, n.10, p.2317-17 26, 1996.

HENRIQUES, L. T.; VALADARES FILHO, S. C.; FONSECA, M. A.; PAULINO, P.V.R.;DETMANN, E.; VALADARES, R. F. D. Avaliação de modelos não-lineares e da relação do consumo voluntário de vacas primíparas e de bezerros com a curva de lactação de vacas Nelore. Revista Brasileira de Zootecnia, v.40, n.6, p.1287-1295, 2011.

HOFFMANN, B. M. Parametrização e validação de um modelo de estimativas das exigências e do desempenho de gado de corte. Piracicaba, SP: ESALQ, 2007. 113p. Dissertação (Mestre em Agronomia) - Escola Superior de Agricultura "Luiz de Queiroz", 2007.

IBGE.Estatística da produção pecuária, 2013. Disponível em <http://www.ibge.gov.br/home/estatistica/indicadores/agropecuaria/producaoagropecuaria/ab ate-leite-couro-ovos_201204_publ_completa.pdf> Acesso em:23/05/2013.

INSTITUT NATIONAL DE LA RECHERCHE AGRONOMIQUE - INRA.(1988) Animentation de bovines, ovinsetcaprins. Ed. R. Jarrige, Paris: Institut National de la RechercheAgronomique.

JENKINS, T.G. \& FERREL, C.L. Lactation characteristics of nine breeds of cattle fed various quantities of dietary energy. Journalof Animal Science, v.70, n.6, p.1652-1660, 1992.

MARCONDES, M. I.; GIONBELLI, M. P.; VALADARES FILHO, S. de C.; CHIZZOTTI, M. L.; PAULINO, M. F. Exigências nutricionais de proteína para bovinos de corte. In:

Exigências Nutricionais de Zebuínos Puros e Cruzados BR-CORTE. $2^{\mathrm{a}}$ Ed. Viçosa, MG: UFV, 2010, p. 119-141. 
MCCARTER, M. N.; BUCHANAN, D. S.; FRAHM, R. R. Comparison of crossbred cows containing various proportions of Brahman in spring or fall calving systems. II. Milk production. Journal of Animal Science, v. 69, p. 77-84, 1991).

METCALF, J. A.; WRAY-CAHEN, D.; CHETTLE, E. E. et al. The effect of dietary crude protein as protected soybean meal on mammary metabolism in the lactating dairy cow. Journalof Animal Science, v. 79, p. 603-611, 1996.

NATIONAL RESEARCH COUNCIL - NRC . Nutrient Requirements of Beef Cattle.7ed. National Academy Press, Washington, DC. 1996. 242p.

NATIONAL RESEARCH COUNCIL - NRC.Nutrient requeriments of beef cattle.update7 ed. National Academic Press. Washington, D.C.:2000. 248 p.

NATIONAL RESEARCH COUNCIL - NRC.Nutrient requirements of dairy cattle.7.ed. NationalAcademic Press. Washington, D.C.: 2001. 381p.

OLIVEIRA, V. de C.Eficiência da utilização de energia alimentar para a produção de bezerros por vacas nelore e mestiças. Campos dos Goytacazes - RJ, UNEF, 2006, 74p. (Mestre em Produção Animal) - Universidade Estadual Do Norte Fluminense Darcy Ribeiro, 2006.

PAULINO, P. V. R. Desempenho composição corporal e exigências nutricionais de bovinos Nelore de diferentes classes sexuais. Viçosa -MG, UFV, 2006. 167p. (Doutorado em Zootecnia) - Universidade Federal de Viçosa, 2006.

PAULINO, P. V. R.; FONSECA, M.A.; HENRIQUES, L. T.; VALADARES FILHO, S. de C.; DETMANN, E. Exigências nutricionais de vacas e bezerros Nelore. In: Exigência Nutricionais de Zebuínos Puros e Cruzados - BR- CORTE, 2a ed. Viçosa, MG: UFV, Suprema Gráfica Ltda. 2010. 193p.

RESTLE, J. PACHECO, P.S.; MOLETTA, J. L. et al. Grupo Genetico e nivel nutricional pos-parto na producao e composicao do leite de vacas de corte. Revista Brasileira de Zootecnia, v.32, n.3, p.585-597, 2003.

REYNOLDS, C. K \& TYRRELL, H. F. Energy Metabolism in lactating beef heifers.Journalof Animal Science, v. 78, p. 2696-2705, 2000.

RIBEIRO, M. N.; PIMENTA FILHO, E. C.; SANTOS, E. S. dos; COSTA, R. G. Fatores genéticos e ambientais que afetam os pesos de bezerros Nelore na fase pré-desmame. Agropecuária técnica, v. 13, n. 1/2, 1992.

SARMENTO D. C. S. Comportamento ingestivo de bovinos em pasto de capim Marandú submetidos a regimes de pastejo. ESALQ, Piracicaba, 2003. 76p. Dissertação (mestrado). Escola superior Luíz de Queiroz, 2003.

SINCLAIR, K.D., YILDIZ, S., QUINTANS, G. et al. Annual energy intake and the performance of beef cows differing in body size and milk potential. Journal of Animal Science, v.66, p.643$655,1998$.

SOLIS, J. C., BYERS, F. M., SCHELLING, G. T.; LONG, C. R.; GREENE, L. W. Mantenance requirements and energetic efficiency of cows of different breed types. Journal Animal Science, v. 66, p. 764-773, 1988. 
SOUZA, J. C. de; SALLES, F. M.; SILVA, L. O. C. da; MOTA, M. F.; FREITAS, J. A. de; MALHADO, C. H. M.; FERRAZ FILHO, P. B. Avaliação de características produtivas em animais da raça Nelore por meio de análise multivariada. Revista Brasileira de Ciência Veterinária, v. 17, n. $3 / 4$, p. $99-103,2010$.

VALADARES FILHO, S. C.;PAULINO, P. V. R.; MAGALHAES, K. A. Exigências Nutricionais de Zebuínos e Tabelas de Composição de Alimentos - BR - CORTE. 1. ed. - Viçosa: UFV,DZO, 2006. 142p. 